\title{
Ширлина Е.Н. \\ Особенности употребления предлогов в австрийском варианте немецкого языка
}

Белгородский государственный наџиональный исследовательский университет

(НИУ «БелГУ»)

(Россия, Белгород)

doi: $10.18411 / s p c-26-03-2018-11$

idsp: 000001:spc-26-03-2018-11

\section{Abstract}

The article deals with the specific characteristics of prepositions used in the German language of Austria, which are continuously changing under the influence of the German language of Germany. The object of the study is prepositions as a part of free prepositionalnominal combinations, of formally fixed prepositional-nominal combinations and prepositions as an element of verbal valence. These changes are observed, first of all, in the speech of the younger generation, and also in the language of the press. The uneven displacement of Austrian variants with variants from the German language of Germany is associated with the varying degree of spread of the dialect, as well as with the cultural proximity to Germany of certain Austrian regions.

В данной статье мы опираемся на концепцию полицентризма, согласно которой литературный немецкий язык в Австрии представляет собой национальную разновидность языка, равноценную немецкому языку в Германии. Однако следует отметить, что применительно к немецкому языку можно говорить об асимметричном полицентризме. Немецкий язык Германии занимает доминирующую позицию по причине того, что на нём говорит большее число людей, благодаря лидирующему экономическому положению Германии, более широкой представленности немецкого языка Германии в СМИ, а также тому, что этот вариант наиболее полно описан и кодифицирован [2, с. 125-126]. Такая асимметрия неизбежно приводит к тому, что в национальном варианте, который использует меньшее число носителей, происходят изменения под влиянием более распространённого и «престижного» варианта.

В рамках данной публикации мы остановимся на изменениях лексикограмматического характера, которые затронули наиболее частотные первообразные, то есть простые полисемантические предлоги в австрийском варианте немецкого языка.

Как известно, лексикографические источники с опозданием реагируют на происходящие в языке изменения, поэтому для начала дадим характеристику особенностей функционирования немецких предлогов, опираясь на данные, зафиксированные в «Словаре австрийского варианта немецкого языка» Дудена 2008 года издания. Представленную в нём информацию о немецких предлогах в австрийском национальном варианте можно разделить на следующие блоки:

1) иное, чем в немецком языке Германии, функционирование предлогов в рамках свободных предложно-именных сочетаний (например, „an“ в значении «нахождение на горизонтальной поверхности» в сочетании с именами существительными мужского и среднего рода: am Kopf, am Land, am Zahnfleisch и т.д.; использование предлога „,bei“ вместо „,an“, „zum“: bei der Kasse, beim Hals heraushängen, beim Fenster hinausschauen и др.);

2) иное, чем в немецком языке Германии, функционирование предлогов в рамках устойчивых по форме (моделированных) предложно-именных сочетаний (использование предлога ,über“ вместо „auf“ в значении «ответная реакция на чужое волеизъявление»: über Antrag, über Erbitten, über Ersuchen и др.);

3) иное, чем в немецком языке Германии, функционирование предлогов как элемента предложного управления глаголов (например, использование предлога „um“ 
вместо „für““ с глаголами „kaufen“, „verkaufen“, „arbeiten“, „schicken“, „ersuchen“: etw. um 10 Euro kaufen) [1, c. 45-46].

В 2012 - 2013 годах австрийский профессор-германист Петер Визингер провёл анкетирование среди 395 студентов младших курсов из разных регионов Австрии и из Южного Тироля. Студенты являлись носителями разных диалектов, но благодаря обучению в гимназии имели представление о стандартном варианте австрийского языка. Анкеты содержали 17 вопросов, которые имели отношение к просодике, морфологии, синтаксису, словообразованию и семантике немецкого языка. Анализ анкет показал, что австрийский вариант немецкого языка всё больше подвергается влиянию немецкого языка в Германии, особенно это касается Форарльберга и Южного Тироля, поскольку они в большей степени ориентированы на германские стандарты, а также нередко ошибочно воспринимают стандартный австрийский вариант как диалектный, верхнеавстрийский или венский [3, с. 118]. Ряд вопросов касался употребления предлогов. Мы остановимся только на тех случаях, которые зафиксированы в вышеупомянутом словаре Дудена.

Что касается употребления предлогов в составе свободного предложноименного сочетания, респонденты выбирали между вариантами „,bei der Kassa“ и „an der Kassa“ (в данном случае разница между австрицизмом „Kassa“ и тевтонизмом „Kasse“ не является принципиальной) и „,aus dem“/,zum“ / „,beim Fenster hinausschauen“. В первом случае «Словарь австрийского варианта немецкого языка» приводит оба варианта (вариант с „ьеi“ в качестве более распространённого) [1, с. 46]. В Вене, Нижней Австрии, Штирии и Каринтии до 90\% опрошенных выбрали вариант с предлогом ,an“, в Верхней Австрии, Зальцбурге и Тироле - 96-97\%, а в Форарльберге $100 \%$ [3, c. 114$]$.

В сочетании „aus dem“/,zum“ / „beim Fenster hinausschauen“, большинство опрошенных (57,5\%) выбрало вариант с aus, 22,7\% c zum, 19,8\% c beim [3, с. 116]. В Южном Тироле и Форарльберге две трети респондентов выбрали предлог zum. В Зальцбурге, Тироле, Каринтии и Штирии четверть и более опрошенных назвали в качестве правильного варианта выражение „,beim Fenster hinausschauen“ [3, с. 116]. Это можно объяснить влиянием разговорной речи, для которой характерно употребление предлога „ьеi“ в локальном значении: bei der Haltestelle stehen, bei der Kurve vorsichtig fahren, bei der Kreuzung abbiegen и т.д.

Также происходят изменения в предложном управлении глаголов. Словарь Дудена даёт вариант употребления глагола „vergessen“ с предлогом „auf“ в значении «забыть что-л. сделать» [1, с. 44]. В целом вариант без предлога выбрали 87\% опрошенных. В баварской Австрии от Тироля до Нижней Австрии и до Бургенланд сильны диалектные влияния: там вариант с предложным управлением выбрали до $20 \%$. В Форарльберге ситуация сложнее: там наблюдается сильное расхождение устной и письменной нормы (последняя ориентирована на нормы немецкого языка в Германии). В Тироле зафиксирована самая низкая частотность употребления глагола с предложным управлением - 6\% [3, с. 115]. Аналогичная ситуация наблюдается и в том случае, когда разница в управлении не связана с семантическими различиями. Так, $85 \%$ опрошенных признали правильным выражение „kaufen um“ и только 15\% „kaufen für“. В Южном Тироле и Форарльберге, которые в большей степени ориентированы на немецкий язык в Германии, треть респондентов выбрала управление с „für“ [5, c. 113].

Изменения также частично затронули моделированные предложно-именные сочетания. Что касается сочетаний с отглагольными именами существительными со значением реакции на чужое волеизъявление, анализ австрийских интернетисточников, проведённый автором статьи, показал, что на сайтах государственных институтов, в языке официальных документов всё ещё встречается характерный австрийский вариант с предлогом „über“ (über Antrag, über Ersuchen, über Aufforderung и др.). В то время как в языке прессы, в том числе, в авторитетных изданиях, например, 
„Standard“, этот вариант в значительной степени вытеснен принятым в качестве нормы в Германии вариантом с ,auf":

VfGH hebt über Antrag des OGH Bestimmungen des Fortpflanzungsmedizingesetzes auf [Официальный сайт Верховного суда Австрии].

„Wahlkarten gibt's auf Antrag“; ÖVP kritisiert FPÖ [www.meinbezirk.at].

Анализ подобных моделированных сочетаний в устной речи носителей австрийского варианта немецкого языка представляется нецелесообразным, поскольку они относятся к официально-деловому стилю и поэтому более характерны для письменной речи. Однако в перспективе мы планируем рассмотреть изменения, которые затронули другие устойчивые по форме предложно-именные сочетания, в частности, конструкции с предлогом „zи“ и абстрактным именем существительным (часто названием праздника) в значении «к определённому моменту времени» (zu Ostern, zu Neujahr, zum Jahreswechsel и др.).

Таким образом, можно сделать вывод о том, что в австрийском варианте немецкого языка непрерывно происходят изменения под влиянием немецкого языка Германии, в том числе на грамматическом уровне. Данные изменения наблюдаются, прежде всего, в речи молодого поколения, а также в языке прессы. Неравномерное вытеснение австрийских вариантов вариантами из немецкого языка Германии связано с различной степенью распространения диалекта, а также с культурной близостью к Германии отдельных регионов.

статья выполнена в рамках стажировки в Институте гуманитарных наук г. Вена, Австрия (InstitutfürdieWissenschaftenvomMenschen) при поддержке гранта Благотворительного фонда культурных инициатив (Фонда Михаила Прохорова)

$$
* * *
$$

1. Duden. Österreichisches Deutsch. Mannheim, Leipzig, Wien, Zürich: Dudenverlag, 2008, 52 S.

2. Peter, Klaus. Sprachliche Normvorstellungen in Österreich, Deutschland und der Schweiz. In: Dimensionen des Deutschen in Österreich: Variationen und Varietäten im sozialen Kontext / Alexandra N. Lenz, Timo Ahlers, Manfred M. Glauninger (Hrsg.). Frankfurt am Main: Peter Lang GmbH, 2015, S. 123 - 147.

3. Wiesinger, Peter. Das österreichische Deutsch in der globalisierten Umwelt: Wandlungen durch bundesdeutsche Einflüsse. In: Dimensionen des Deutschen in Österreich: Variationen und Varietäten im sozialen Kontext / Alexandra N. Lenz, Timo Ahlers, Manfred M. Glauninger (Hrsg.). Frankfurt am Main: Peter Lang GmbH, 2015, S. 91-122.

\section{Semenova E.M. \\ «Uniformity - diversity» as the basic archetypical metaphorical opposition of American linguistic culture}

SPbUTME

(Russia, Saint-Petersburg)

doi: $10.18411 /$ spc-26-03-2018-12

idsp: 000001:spc-26-03-2018-12

Over the last decades more and more countries throughout the world have been facing increasing ethnic, cultural and linguistic diversification within their borders. It's becoming crucially vital to come to terms with these changes, which are now occurring not only in policy but our everyday life as well. A great deal of research in the Humanities is focusing nowadays on a range of topics related to multiculturalism from the perspectives of different disciplines among which linguistics occupies one of the prominent places.

Modern forms of the world perception, broadening and making endless the borders of cognition due to the developing of new technologies and mass-media means of transmitting information at the same time "deactualizes" the necessity to "switch on" the individual senses 